3 Tukiainen P, Taskinen E, Holsti P, Korhola O, Valle M. Prognosis of cryptogenic fibrosing alveolitis. Thorax 1983;38:349-55.

4 Weissler JC. Idiopathic pulmonary fibrosis: cellular and molecular pathogenesis. Am F Med Sci 1989;297:91-104.

5 World Health Organisation. International classification of diseases 1975 9 th revision. Geneva: WHO, 1977.

6 Office of Population Censuses and Surveys. Mortality statistics 1979-1987. London: HMSO, 1980-8. (Series DH2, Nos 6-14.)

7 SPSS Incorporated. Statistical package for the social sciences- $X$ users guide. $2 \mathrm{nd}$ ed. New York: McGraw Hill, 1986.

8 Numerical Algorithms Group. Generalised linear interactive modelling system, release 3.77. Oxford: Royal Statistical Society, 1986

9 Office of Population Censuses and Surveys. Census 1981. National report. Great Britain part 2. London: HMSO, 1983. (CEN 81 NR(2).)

10 Johnston IDA, Bleasdale C, Hind CRK, Woodcock AA. Cryptogenic fibrosing alveolitis: accuracy of diagnostic coding in hospital admissions. Thorax 1989;44:871P.

11 Office of Population Censuses and Surveys. Mortality statistics 1984. London: HMSO, 1985. (Series DH2, No 11 .)
12 Carrington CB, Gaensler EA, Coutu RE, Fitzgerald MX, Gupta RG. Natural history and treated course of usual and desquamative interstitial pneumonia. N Engl F Med 1978;298:801-9.

13 Stack BHR, Choo-Kang YFJ, Heard BE. The prognosis of fibrosing alveolitis. Thorax 1972;27:535-42.

作

15 Fulmer JD, Sposovska MS, Von Gal ER, Crystal RG, Mittal KK. Distributio of HLA antigens in idiopathic pulmonary fibrosis. Am Rev Respir Dis of HLA antigens

16 Turton CWG, Morris LM, Lawler SD, Turner-Warwick M. HLA in cryptogenic fibrosing alveolitis. Lancet 1978; i:507-8.

17 Iwai K, Nakajima T, Miyagi Y, et al. Epidemiological studies on idiopathic diffuse interstitial fibrosis of the lung. Nippon Kyobu Shikkan Gakkai Zasshi 1980;18:800-8.

18 Hamman L, Rich AR. Acute diffuse interstitial fibrosis of the lungs. Bulletin of the Johns Hopkins Hospital 1944;74:177-212.

(Accepted 15 August 1990)

\title{
Home treatment for acute psychiatric illness
}

\author{
C Dean, E M Gadd
}

\begin{abstract}
Objective-To determine the factors influencing the successful outcome of community treatment for severe acute psychiatric illnesses that are traditionally treated in hospital.

Design-All patients from a single electoral ward who were either admitted to hospital or treated at home over a two year period (1 October 1987 to 30 September 1989) were included in the study and their case notes audited. The second year of the study is reported.
\end{abstract} ham.

Setting-Electoral ward of Sparkbrook, Birming-

Subjects-99 Patients aged 16-65 with severe acute psychiatric illness.

Results -65 Patients were managed by home treatment alone; 34 required admission to hospital. The location of treatment was significantly (all $\mathbf{p}<0.05$ ) influenced by social characteristics of the patients (marital state, age (in men), ethnicity, and living alone) and by characteristics of the referral (occurring out of hours; assessment taking place at hospital or police station). DSM-III-R diagnosis was more weakly associated with outcome. Violence during the episode was significantly related to admission, although deliberate self harm was not.

Conclusions - Home treatment is feasible for most patients with acute psychiatric illness. A 24 hour on call assessment service increases the likelihood of success because admission is determined more strongly by social characteristics of the patient and the referral than by illness factors. Admission will still be required for some patients. A locally based mental health resource centre, a 24 hour on call service, an open referral system, and an active follow up policy increase the effectiveness of a home treatment service.

\section{Introduction}

Most serious psychiatric illnesses are chronic relapsing conditions. Admission to a psychiatric hospital for the acute relapses does little to influence the long term course of the diseases, and with the move away from institutional care it offers only very short respite to the relatives.

During the past 30 years several investigators have examined alternatives to hospital admission and the effect of such alternatives on patients and their relatives both during and after the episode of illness. Several studies examined the feasibility of treating patients in their own homes. Fenton et al were able to prevent admission in $62 \%$ of their 76 home care patients during a one year study, although $45 \%$ of those presenting for admission were excluded from the trial. ${ }^{1}$ Stein and Test reported a study in Madison, Wisconsin, where 130 patients who presented for admission to hospital were randomly allocated to either hospital or community treatment. ${ }^{2}$ In the year following treatment the community group had fewer admissions, fewer psychiatric symptoms, and better social functioning and reported more satisfaction than the group treated in hospital. This study was replicated by Hoult and Reynolds in Sydney, Australia, with broadly similar findings, ${ }^{3}$ and they also found that patients and their relatives reported more satisfaction with the community treatment. ${ }^{4}$ Pai and Kapur examined home treatment for schizophrenic patients in Bangalore, India, and showed a reduction in family burden at six month follow up for those who had been treated at home. ${ }^{5}$ A number of earlier studies reported similar findings: the group treated at home had a better outcome. - $^{6-8}$

Patients dependent on alcohol or drugs and those with organic brain syndromes have been excluded from all trials of home treatment. The older studies excluded patients without family or surrogate and those who were suicidal or homicidal. No study has shown that it is possible to avoid admission entirely. Grad and Sainsbury provided the only report of a total adult psychiatric service in Chichester, England, showing that an expansion in community facilities and increased domiciliary visiting by the psychiatric team greatly reduced the total number of admissions in comparison with the traditional service in Salisbury, which was demographically similar. ${ }^{9}$ None of the reported studies of home treatment were carried out in Great Britain and all were done 10-20 years ago, making it difficult to generalise the findings to current psychiatric practice in Britain.

We report a service in Birmingham that provides a total psychiatric service to a community by using home treatment principles. Central Birmingham psychiatric services are organised in sectors, with each general psychiatry consultant being responsible for patients under 65 in one or two electoral wards. CD is the consultant responsible for the inner city electoral ward of Sparkbrook, which has a population of 25728 (1981 census). Over half the inhabitants are from the New Commonwealth or Pakistan, $11 \%$ from the Irish Republic, and 35\% from the United Kingdom. The population is mostly social classes III manual, IV, or V; only $12 \%$ are in social class II or III non-manual of the Registrar General's classifications. Unemployment is Dr Dean. 
three times the national average. This deprived area has a Jarman score ${ }^{10}$ of +62 (range -62.52 to $+72 \cdot 95$ ), which puts it in the worst 10 of the 9265 electoral wards in England and Wales.

Over the past two and a half years a service has been set up whereby seriously ill patients (that is, those who are suicide risks, aggressive, non-compliant, or severely psychotic) who would normally have been treated in hospital for their acute relapses are treated at home. Before setting up the home treatment service the district had obtained funding for a resource centre in Sparkbrook from the special mental health development initiative of the Department of Health and Social Security. This resource centre provides the centre for the home treatment service staff and the focal point for referrals. The resource centre is run by a multidisciplinary team and is a joint venture of the departments of health and social services. The manager is a social worker and the deputy manager is a charge nurse. An occupational therapist is employed by the health service, and two instructors are employed by social services. The district psychologist does one or two sessions at the centre, and a psychology technician is based at the centre. The resource centre provides a five day a week (including bank holidays) "drop in" service for patients with chronic mental illness and specific group activities for such patients and for patients with more minor illnesses. It also provides a service, where required, for patients who are acutely ill and on home treatment and support groups for relatives.

To the three community psychiatric nurses working in Sparkbrook have been added two community psychiatric nurses specifically for the home treatment service and two nursing assistants. Two social workers also work in the electoral ward. The consultant provides a total of five sessions to the electoral ward, and there is a full time registrar based at the resource centre. During the year reported there was also seven sessions' input from a senior registrar. Five of the staff speak Asian languages. The resource centre and the home treatment service are run flexibly so that all the staff work in the centre and in the community depending on the needs of individual clients.

The service has been well received by Good Practices in Mental Health, the National Schizophrenia Fellowship, and Mind. Before the introduction of the service there had been a high bed usage by patients from Sparkbrook with an average of 100 admissions a year and a mean bed occupancy of 18 which was in keeping with the high psychiatric morbidity.

\section{Patients and methods}

The service accepts referrals from any agency, general practitioner, health visitor, patient, relative, etc. Urgent referrals are seen as soon as possible and certainly on the day of referral by a nurse and a doctor. Wherever possible the patients are assessed initially by at least one member of staff who speaks their language. Thereafter the staff have a mixed caseload but always have the benefit of advice from someone who speaks the appropriate language if this is required. All the staff carry a limited number of drugs (thioridazine, chlorpromazine, haloperidol, amitriptyline, procyclidine, fluphenthixol decanoate) so that initial drug treatment can be started immediately if this is required. If patients are regarded as suitable for home treatment they have a full "work up" as they would in hospital with a history, case summary, and physical examination and investigations. The team notifies the general practitioner and the 24 hour care of the patients is taken over as if they were in hospital. The doctor carries a bag with all the necessary instruments, venepuncture equipment and request forms, drugs, and a prescription pad. A folder containing continua- tion sheets, a physical examination sheet, and prescription card is made up for each patient receiving home treatment and is left in the patient's home. On the cover are instructions about how to reach the 24 hour on call home treatment nurse. All staff members record their assessment at each visit on the continuation sheets. At the end of home treatment all these records are filed in the patient's main hospital records. Initially the patients are visited at least once a day by a doctor and a nurse; often in the first few days they require visits several times a day. Medication is dispensed daily when this is necessary for compliance or safety reasons. The nursing assistants sometimes spend several hours at a time in the patient's home supporting the relatives or allowing them to be out of the house for a while. The patients are reviewed twice a week in multidisciplinary meetings, and at that time a decision is made whether to continue them on home treatment or to discharge them to outpatient or day care. At any time a decision can be made to admit a patient to hospital if home treatment is no longer regarded as the appropriate treatment.

When discharged from home treatment each patient has a discharge plan, and patients are followed up at outpatient clinics, which are run at the resource centre, or visited on a regular basis at home if they are not able to attend. They and their relatives are asked to contact us immediately if there are any early signs of relapse. The patients are also offered whatever services they require from the centre-for example, drop in facility, group activities, help from social workers.

All patients from Sparkbrook electoral ward aged 16-65 who were treated at home or admitted to hospital with acute psychiatric illness during the two year period 1 October 1987 to 30 September 1989 were included in the study and their case notes audited; the six months before the introduction of the resource centre were not studied. Patients admitted to the other hospitals in the district and under another consultant were also included. Of those assessed, not all were suitable for home treatment, and some patients required admission to hospital after receiving home treatment. The characteristics of patients managed by home treatment alone were compared with those of patients who were admitted to hospital at any point during their illness. We report the results of the year of the study from October 1988, after the introduction of the 24 hour on call service. The results of the previous year are reported elsewhere. ${ }^{11}$

\section{Results}

In the first year 38 episodes ( 37 patients) were treated at home and $54(45)$ in hospital. ${ }^{11}$ (There was a total of 80 patients as two patients had both a home treatment and a hospital admission). In the second year, after the introduction of the 24 hour on call service, 65 episodes ( 56 patients) were treated at home and 34 (24) in hospital. (There was a total of 74 patients; six had both kinds of treatment.) Of those admitted in the second year, 12 were assessed as being unsuitable for home treatment, 15 were admitted without assessment, and seven were admitted after a period (mean 32 days; range 2-117 days) of home treatment. The average bed occupancy over the two and a half years for the electoral ward of Sparkbrook fell from 18 to five: falling during the first six months from 18 to 10 , static during the next 12 months at 10 , and falling in the year following the introduction of the 24 hour on call service from 10 to five.

Characteristics of the referral and the assessment were found to significantly influence outcome. Of the 65 home treatment patients, $55(85 \%)$ were assessed during office hours ( 9 am to $5 \mathrm{pm}$ ) compared with 21 $(62 \%)$ of the 34 admissions $\left(\chi^{2}=6 \cdot 5 ; \mathrm{df}=1, \mathrm{p}<0.02\right)$. 
The location of assessment was also different in the two groups, with the admissions being assessed more often at a hospital or police station and home treatment patients at home or in outpatients (table I).

Social characteristics influenced outcome. Significantly more of the admissions than patients receiving home treatment $\left(15(44 \%) v 12(18 \%) ; \chi^{2}=7 \cdot 4\right.$, $\mathrm{p}<0.01)$ were living alone; the admitted patients were less likely to be married (11 (32\%) $v 37(57 \%) ; \chi^{2}=5 \cdot 4$, $\mathrm{p}<0.05)$; and home treatment patients were more likely to have children under 5 at home $(22(34 \%) v$ $\left.4(12 \%) ; \chi^{2}=5 \cdot 6, p<0.02\right)$. Although there was no difference in sex ratio between the two groups, men who were admitted were significantly younger than those treated at home (mean ages 26 v. 40, $t=4 \cdot 76$, $\mathrm{p}<0.001$ ). Asian patients not born in Britain were more likely to be treated at home than admitted $\left(30(46 \%) v 7(21 \%) ; \chi^{2}=6 \cdot 2, \mathrm{p}<0 \cdot 02\right)$. When patients of Asian origin born in Britain were included the difference was not significant $(31(48 \%) v 13(38 \%))$.

Admitted patients were more likely to have been admitted previously $\left(29(85 \%) v 36(55 \%) ; \chi^{2}=8 \cdot 86\right.$, $\mathrm{p}<0.01$ ), and to have had a previous compulsory admission (19 (56\%) v $\left.23(35 \%) ; \chi^{2}=3.84, \mathrm{p}<0.05\right)$. The admitted patients were more likely to have shown violence during the episode than those treated at home $\left(15(44 \%) v 9(14 \%) ; \chi^{2}=11 \cdot 14, \mathrm{p}<0.001\right)$ but there was no difference between the two groups in terms of self harm $(6(17 \cdot 6 \%) v 5(7 \cdot 7 \%))$. Patients of all diagnostic groups were treated successfully at home (table II) but there was a non-significant tendency for more depressed patients than expected (29 observed, 24 expected) to be treated at home and more manic patients (12 observed, 9 expected) to be treated in hospital $\left(\chi^{2}=7 \cdot 37 ; \mathrm{df}=3, \mathrm{p}<0 \cdot 1\right)$. Patients who were suicidal were successfully treated at home, and there were no suicides or homicides during the two and a half year period.

The main reasons why some of those assessed for home treatment needed at some point to be admitted to hospital were violence, delusions about the family or pathological family dynamics, admission following assessment of the patient in police custody, refusal to take prescribed drugs, recurrent overdosing, and concurrent physical problems.

TABLE I-Location of assessment. Figures are numbers (percentages) of patients

\begin{tabular}{lcc}
\hline & $\begin{array}{c}\text { Patients } \\
\text { treated } \\
\text { at home }\end{array}$ & $\begin{array}{c}\text { Patients } \\
\text { admitted to } \\
\text { hospital }\end{array}$ \\
\hline $\begin{array}{l}\text { Home } \\
\text { Hospital }\end{array}$ & $\begin{array}{c}51(78) \\
3(5)\end{array}$ & $\begin{array}{c}13(38) \\
13(38)\end{array}$ \\
$\begin{array}{l}\text { Outpatient department or general practitioner's } \\
\text { surgery }\end{array}$ & $11(17)$ & $\begin{array}{c}5(15) \\
3(9)\end{array}$ \\
\hline Police station & 65 & 34 \\
\hline Total & 65 & 34 \\
\hline
\end{tabular}

$\chi^{2}=27 \cdot 04 ; \mathrm{df}=3 ; \mathrm{p}<0 \cdot 001$.

TABLE II-Diagnosis according to DSM-III-R criteria. Figures are numbers (percentages) of patient

\begin{tabular}{llc}
\hline $\begin{array}{l}\text { Diagnosis } \\
\text { (DSM-III-R codes) }\end{array}$ & $\begin{array}{c}\text { Patients } \\
\text { treated } \\
\text { at home }\end{array}$ & $\begin{array}{c}\text { Patients } \\
\text { admitted to } \\
\text { hospital }\end{array}$ \\
\hline $\begin{array}{l}\text { Depression }(296 \cdot 52-296 \cdot 54 ; 296 \cdot 32-296 \cdot 34 ; \\
\quad 296 \cdot 22-296 \cdot 25)\end{array}$ & $29(45)$ & $7(21)$ \\
$\begin{array}{l}\text { Manic, mixed affective, and schizoaffective } \\
\text { manic }(296 \cdot 41-296 \cdot 45 ; 296 \cdot 61-296 \cdot 62 ; \\
295 \cdot 70-\text {-bipolar-manic) type }\end{array}$ & $14(22)$ & $12(35)$ \\
$\begin{array}{l}\text { Schizophrenia or other psychoses }(295 \cdot 10-295 \cdot 6 ; \\
295 \cdot 70 \text {-depressive type; } 297 \cdot 10 ; \\
\text { 298.10-298.90) }\end{array}$ & $16(25)$ & $8(23)$ \\
$\begin{array}{l}\text { Other: neuroses, alcohol dependence } \\
(300 \cdot 00-300 \cdot 40 ; 303 \cdot 90 ; 309 \cdot 00-309 \cdot 40)\end{array}$ & $6(9)$ & $7(21)$ \\
\hline $\begin{array}{l}\text { Total } \\
\chi^{2}=7 \cdot 37 ; \mathrm{df}=3 ; \mathrm{p}<0 \cdot 1 .\end{array}$ & 65 & 34 \\
\hline
\end{tabular}

\section{Discussion}

As did the other reported studies we found that it was possible to treat at home most (about two thirds) of patients who would otherwise have been admitted to hospital for treatment. Unlike the other studies we had no exclusion criteria. This is, to our knowledge, the only reported study of home treatment in Great Britain and the only one in a deprived inner city area.

We were not able to examine which elements of our service were responsible for the fall in bed occupancy, but it is worth noting that the number of patients treated at home increased (to $65 \%$ from $41 \%$ ) after the introduction of the 24 hour on call system. The other ingredients of our service which might have been responsible for the reduction in admissions are the existence of the community based mental health resource centre, our policy of rapid response to referrals from any agency, and our proactive approach to missed appointments and maintenance injections. These factors may result in patients receiving treatment earlier in their illness than in a traditional hospital based service.

As reported by Hoult and Reynolds ${ }^{3}$ this type of service is well liked by the patients and their relatives, who have much more face to face contact with staff than patients treated in hospital. We also found that because the patients know we will not necessarily admit them they are more likely to disclose early symptoms of their illness.

Our findings may not apply generally. The area served is very compact, facilitating frequent visiting, and has a high percentage of Asian residents, with the advantage of good family support. On the other hand, few electoral wards are as socially deprived and lacking in community support as is Sparkbrook. Hence we have found that this method of treatment is suitable for some patients who live alone; they comprise $18 \%$ of our home treatment patients, a similar proportion to that treated by Reynolds and Hoult (19\%).

Because of the reduction in bed usage some of the revenue saved was used for nurses specifically for home treatment. Many of the patients who are admitted, however, require intensive nursing and more staff are needed than on a standard psychiatric inpatient unit.

In view of the consistently positive findings for this type of treatment it is difficult to know why it has not been more universally adopted. We are now comparing the home treatment service in Sparkbrook with the neighbouring hospital based service in Small Heath, Birmingham. We shall be examining speed of recovery, outcome, burden to relatives, and patients' and relatives' satisfaction.

1 Fenton FR, Tessier L, Struening EL. A comparative trial of home treatmen and hospital psychiatric care: one year follow up. Arch Gen Psychiatry and hospital psych

2 Stein LI, Test MA. Alternative to mental hospital treatment. I. Conceptual model, treatment programme and clinical evaluation. Arch Gen Psychiatry 1980;37:392-7.

3 Hoult JE, Reynolds I. Community orientated treatment compared to psychiatric hospital orientated treatment. Soc Sci Med 1984;,18:1005-10.

4 Reynolds I, Hoult JE. The relatives of the mentally ill; a comparative trial of community-orientated and hospital orientated psychiatric care. 7 Nerv Ment Dis 1984;172:480-9.

5 Pai S, Kapur RL. Impact of treatment intervention on the relationship between dimensions of clinical psychopathology, social dysfunction and burden on the family of psychiatric patients. Psychol Med 1982;12:651-8.

6 Langsley DG, Flomenhaft K, Machotka P. Follow up evaluation of family crisis therapy. Am f Orthopsychiatry 1969;39:753-9.

7 Mosher LR, Menn A, Mathews SM. Soteria: evaluation of a home-based treatment for schizophrenia. Am f Orthopsychiatry 1975;45:455-67.

8 Polak PR, Kirby MW. A model to replace psychiatric hospitals. F Nerv Ment Dis 1976;162:13-22.

$9 \mathrm{Grad}$ J, Sainsbury P. The effects that patients have on their families in a community care and a control psychiatric service - a two year follow up. Brf Psychiatry 1968;114:265-78.

10 Jarman B. Underprivileged areas: validation and distribution of scores. BrMed f 1984;289:1587-92.

11 Dean C, Gadd E. An inner city home treatment service for acute psychiatric patients. Bulletin of the Royal College of Psychiatrists 1989;13:667-9.

(Accepted 23 August 1990) 